\title{
PELLETIZATION OF Anthracophyllum discolor FOR WATER AND SOIL TREATMENT CONTAMINATED WITH ORGANIC POLLUTANTS
}

\author{
O. Rubilar $^{1^{*}}$, S. Elgueta ${ }^{1}$, G. Tortella ${ }^{1}$, L. Gianfreda ${ }^{2}$, MC. Diez ${ }^{1}$ \\ ${ }^{1}$ Scientific and Technological Bioresource Nucleus, Universidad de La Frontera, \\ PO Box 54-D Temuco, Chile. ${ }^{2}$ Dipartimento di Scienze del Suolo, della Pianta, dell'Ambiente e \\ delle Produzioni Animali, Universita` di Napoli Federico II, via Universita` 100, 80055 Portici, \\ Naples, Italy.*Corresponding author: orubilar@ufro.cl
}

\begin{abstract}
Pellets of the white-rot fungus Anthracophyllum discolor with activated carbon and sawdust (complex pellets) were formulated for the degradation of lignin in water and the bioremediation of soil contaminated with pentachlorophenol (PCP). The complex pellets were formed by a center of activated carbon and sawdust surrounded by fungal mycelium, whereas simple pellets consisting of only mycelium were hollow spheres. Degradation of lignin was performed in an airlift reactor at initial lignin concentration of $1000 \mathrm{mg} \mathrm{L}^{-1}$ and the fungal pellets were re-used two times in batch operations. Complex pellets degraded lignin by 87 and $72 \%$ in the first and second cycle, respectively, and they were significantly more effective than simple pellets. In addition, complex pellet showed higher manganese peroxidase activity in the reactor. For the bioremediation of soil contaminated with PCP (150 mg kg-1 of soil) the pellets were added to soil surface. PCP degradation in soil with complex pellets was $85 \%$ at 28 days of bioaugmentation, being higher than in soil with simple pellet. A fungus growth was also observed only in soil with complex pellet. Sawdust and activated carbon appear to be suitable carriers of $A$. discolor for degradation of organic pollutants in wastewater and soil.
\end{abstract}

Keywords: White-rot fungi, lignin, airlift reactor, pentachlorophenol, soils

\section{INTRODUCTION}

The pulp and paper processing industries annually produce several billions of liters of colored, often toxic and harmful wastewaters all over the world. The color of the effluent is generally associated with compounds of high molecular weight such as lignin and its derivatives. (Milestone et al., 2007). In Chile, the most important source of these colored effluents is the chlorine-bleaching process of the pulp and paper mills. Production reaches about 3.4 and 1.2 million tons per year of pulp and paper, respectively (PPI, 2005), discharging large volumes of effluents with high lignin content even after activated sludge treatment (Diez et al., 2002).

On the other hand, the unbleached pulp in bleached kraft mills the lignin is degraded by chorination of phenolic residues generating chlorinated phenolic compounds such as pentachlorophenol (PCP) (Sant'Anna, 1992). The PCP is a toxic pollutant that causes significant 
environmental impacts not only to the ecosystem but also to human health (Taylor et al., 2005). Therefore, these effluents can be discharged into surface waters and/or soil represents a serious ecological problem.

Biological processes for treatment of wastewater and contaminated soil have been of much biotechnological interest, because they allow cost effective and environmental friendly methods for the cleaning up of polluted environments. The high toxicity of some organic pollutants has, however, caused inhibition and death of various microorganisms, preventing the degradation process. For this reason several studies have been devoted to find new organisms capable of degrading organic pollutants and, at the same time, to implement technologies to protect these microorganisms from the competition by indigenous microorganisms in contaminated soils and wastewaters.

White-rot fungi (WRF) are organisms capable to tolerate and degrade higher concentrations of diverse persistent organic compounds as has been reviewed by Pointing (2001) and Tortella et al. (2005). The ability of WRF to degrade pollutants has been attributed to the action of non-specific extracellular ligninolytic enzyme systems, composed principally of laccases, lignin peroxidases (LiP) and manganese peroxidases $(\mathrm{MnP})$. On the other hand, the filamentous multicellular colonial form of these organisms provides both a high cell to substrate ratio and a mechanical adjunct to substrate breakdown (Pointing, 2001).

Environmental conditions and genetic factor contribute to determine the particular morphological form of WRF when they are grown in liquid medium (Žnidaršic and Pavko, 2001; Lin et al., 2007).
Three principal morphological forms are possible: pellets which are spherical agglomerates of hyphaes, mycelia, i.e. the free mycelium dispersed throughout the culture medium and, clump or small loose mycelia aggregated, present in a dispersed growth form (Žnidaršic and Pavko, 2001; Lin et al, 2007). Therefore, a good control of the factors that affect mycelia morphology in liquid medium must be considered for applications of WRF in soil and wastewater bioremediation processes. Studies by Zhang et al. (2000) and Ortega-Clemente et al., (2007) demonstrated that pellet formation for biotechnological purpose can be optimized by immobilization in/on organic and inorganic supports. On the other hand, when the fungi are grown in the soil, several factors such as low nutrient availability, environmental conditions, and indigenous microorganism, among others, can strongly affect the viability of the fungal cultures (Lestan and Lamar, 1999; Walter et al., 2004; Rubilar et al., 2007). Therefore, appropriate fungal inocula are of fundamental importance for a good performance of WRF in soil bioremediation.

One of the main factors leading to variable treatment effectiveness is the approach to inoculum formulation, production, delivery and application to soil or water. Several investigations have shown that different types of organic and inorganic supports allow the formation of fungal pellets providing structural and nutritional functions (Lestan and Lamar, 1999; Fomina and Gadd, 2002; Walter et al., 2004; Rubilar et al., 2007, Levin et al., 2008; Mohammadi and Nasernejad, 2009). These supports may provide protection to the cell from various environmental stresses, improve fungal 
survival (Cassidy et al., 1996) and provide resistance to competition by indigenous microorganism (Lestan et al., 1998). Although the use of support for pellet formation has a key role in degradation process by WRF, no information is available on the viability of fungal pellets when used in wastewaters and contaminated soil. The main objective of this study was the preparation of A. discolor pellets with activated carbon and sawdust for be used in the degradation of organic pollutants in an airlift reactor and in contaminated soil.

\section{MATERIALS AND METHODS}

\section{Chemicals}

Pentachlorophenol (98\% purity) and alkali lignin, with low sulphonate content, were obtained from Sigma-Aldrich. Activated carbon power (particle size less than $100 \mu \mathrm{m}$ ) was obtained from Merck Co. Pine sawdust of particle size less than $0.5 \mathrm{~mm}$ was used. The chemical characteristics of pine sawdust were: 37.4 $\pm 1.3 \%$ carbon, $0.12 \pm 0.02 \%$ nitrogen, $\mathrm{C} / \mathrm{N}$ ration: $310.5 \pm 66.2$. The analyses were done according with methodology described in APHA et al. (2000).

\section{Microorganism}

A white-rot fungus Anthracophyllum discolor, isolated from decayed wood in the rain forest of southern Chile (culture collection of the Environmental Biotechnology Laboratory of the University of La Frontera, Chile) was used in this study. The fungus was transferred from slant tubes (maintained at $4^{\circ} \mathrm{C}$ and transferred every 6 months) to malt extract agar plates $\left(15 \mathrm{~g} \mathrm{~L}^{-1}\right.$ agar, 3.5 $\mathrm{g} \mathrm{L}^{-1}$ malt extract, and $10 \mathrm{~g} \mathrm{~L}^{-1}$ glucose) and kept at $30^{\circ} \mathrm{C}$ for $5-7$ days before being used for inoculum preparation.

\section{Preparation of inoculum}

$100 \mathrm{~mL}$ of modified Kirk medium contained $10 \mathrm{~g} \mathrm{~L}^{-1}$ glucose, $2 \mathrm{~g} \mathrm{~L}^{-1}$ peptone, $2 \mathrm{~g} \mathrm{~L}^{-1} \mathrm{KH}_{2} \mathrm{PO}_{4}, 0.5 \mathrm{~g} \mathrm{~L}^{-1} \mathrm{MgSO}_{4}$, $0.1 \mathrm{~g} \mathrm{~L}^{-1} \mathrm{CaCl}_{2}, 2 \mathrm{mg} \mathrm{L}^{-1}$ thiamine, and mineral salts $\left(10 \mathrm{ml} \mathrm{L}^{-1}\right)$ (Moreira et al., 1997) was placed in Fernsbach flasks, inoculated with five malt agar plugs (6 $\mathrm{mm}$ diameter) of active mycelium of $A$. discolor and incubated at $30^{\circ} \mathrm{C}$. After 7 days, the fungal mycelium was aseptically homogenized in a sterile blender for 1 min and stored at $4^{\circ} \mathrm{C}$ as fungal inoculum for further pellet formation.

\section{Preparation of pellets}

Two types of pellets were prepared: simple (only mycelium) and complex (mycelium immobilized on sawdust and powered activated carbon). Both pellets were prepared in Erlenmeyer flasks containing $40 \mathrm{ml}$ of modified Kirk medium. Simple pellets were prepared by the addition of $2 \mathrm{~mL}$ of fungal inoculum (30 mg dry basis approximately) to the flask. The complex pellets were prepared by mixing 15/15/30 mg dry basis of sawdust/powdered activated carbon/ mycelium (Ortega-Clemente et al., 2007).

The flask cultures were incubated in a rotary shaker at $100 \mathrm{rpm}$ and $30^{\circ} \mathrm{C}$ for 5 days. Simple spherical mycelium pellets and complex spherical mycelium pellets with a black core of activated carbon were formed, harvested with a sterilized stainless steel wire mesh, and stored at $4^{\circ} \mathrm{C}$ for assays performed in airlift bioreactor for lignin degradation and flasks for PCP degradation in soil, respectively.

\section{Preparation of soil}

An Andisol soil collected from the Temuco Series, located in southern Chile was used for the experiments. The soil was collected at 0-20 cm depth, air dried 
at room temperature, sieved to select a particle size lower than $2 \mathrm{~mm}$, and stored at $4^{\circ} \mathrm{C}$ before used. The characteristics of the soil are shown in Table 1. Sterile soil, twice consecutively autoclaved at $121^{\circ} \mathrm{C}$ for 40 minutes, was used as abiotic control. The soil was spiked with a stock solution of PCP (Aldrich, 98\% of purity) diluted in acetone to reach a final concentration of 150 PCP kg-1 soil, homogenized by vigorous shaking and kept under a flow hood for $24 \mathrm{~h}$ until the solvent evaporated.

Table 1. Physico-chemical characteristics of the soil

\begin{tabular}{lc}
\hline Parameter & Andisol \\
\hline $\mathrm{pH}($ in water) & $5.90 \pm 0.20$ \\
$\mathrm{~N}(\%)$ & $0.72 \pm 0.02$ \\
$\mathrm{C}(\%)$ & $8.06 \pm 0.95$ \\
$\mathrm{P}\left(\mathrm{mg} \mathrm{kg}^{-1}\right)$ & $23.00 \pm 2.46$ \\
$\mathrm{MO}(\%)$ & $14.01 \pm 1.68$ \\
$\mathrm{C} / \mathrm{N}$ & $11.22 \pm 1.25$ \\
\hline
\end{tabular}

Lignin degradation by simple and complex pellets of $A$. discolor in an airlift bioreactor.

The experiment was carried out in two airlift bioreactor of $2.4 \mathrm{~L}$ (working volume of 2 L) as duplicate (Figure 1). The bioreactor was sterilized and then aseptically filled with modified Kirk medium and lignin at final concentration of $1000 \mathrm{mg} \mathrm{L}^{-1}$ approximately and inoculated with fungal pellets.

The inoculum consisted of 5 Erlenmeyer flasks containing the simple and complex pellets as described above, corresponding to $0.4 \mathrm{~g} \mathrm{~L}^{-1}$ of biomass in the reactor for each pellet type. Two batch operations were also conducted in the same reactor with the same initial concentration of lignin (1000 mg $\mathrm{L}^{-1}$ approximately). Moreover, after glucose depletion glucose and glucose/peptone were added to reach concentrations of $4 \mathrm{~g}$ $\mathrm{L}^{-1}$ and $0.8 \mathrm{~g} \mathrm{~L}^{-1}$, respectively.

The airlift reactors were operated at $30^{\circ} \mathrm{C}$ by circulation of temperaturecontrolled water. Air was supplied to the bioreactor continuously at a rate of $1.5 \mathrm{~L}$ $\min ^{-1}$. The $\mathrm{pH}$ was not controlled (allowed to vary freely). Periodically $1.5 \mathrm{~mL}$ of samples were collected during 28 days. Pentachlorophenol (PCP) removals in soil by simple and complex pellets of $A$. discolor. The assay was performed in 100 $\mathrm{mL}$ Erlenmeyer flasks containing $10 \mathrm{~g}$ soil (dry weight) contaminated with 150 mg PCP $\mathrm{kg}^{-1}$ soil. The soil surface was inoculated with 50 simple and complex pellets corresponding to $0.5 \mathrm{~g}$ of wet biomass approximately of $A$. discolor. All flasks were wet with $4.5 \mathrm{~mL}$ of sterile distilled water, in order to provide $35 \%$ humidity and incubated at $25^{\circ} \mathrm{C}$ in total darkness for 25 days. The $\mathrm{MnP}$ activity and residual PCP concentration were measured each five days. The abiotic control (sterile soil without fungus) was also incubated under the same conditions. All assays were run in triplicate

\section{Analytical methods}

To evaluate $\mathrm{MnP}$ activity in the bioreactor samples $(1.5 \mathrm{~mL})$ were extracted aseptically and centrifuged at $6000 \mathrm{rpm}$ for $10 \mathrm{~min}$, while in the soil an extraction of $\mathrm{MnP}$ activity was required. To each flask containing soil $(10 \mathrm{~g}) 5 \mathrm{~mL}$ of 250 $\mathrm{mM}$ sodium malonate $(\mathrm{pH} 4.5)$ were added.

The obtained suspension was agitated for $20 \mathrm{~min}$ at $300 \mathrm{rpm}$ in an orbital shaker and an aliquot of $1.5 \mathrm{~mL}$ of supernatant was centrifuged at $6000 \mathrm{rpm}$ for $10 \mathrm{~min}$. In both assays the samples were run in duplicated and the MnP activity was measured in the supernatant by monitoring the oxidation of 2,6dimethoxyphenol (DMP) at $468 \mathrm{~nm}$. The reaction mixture contained $50 \mathrm{mM}$ 


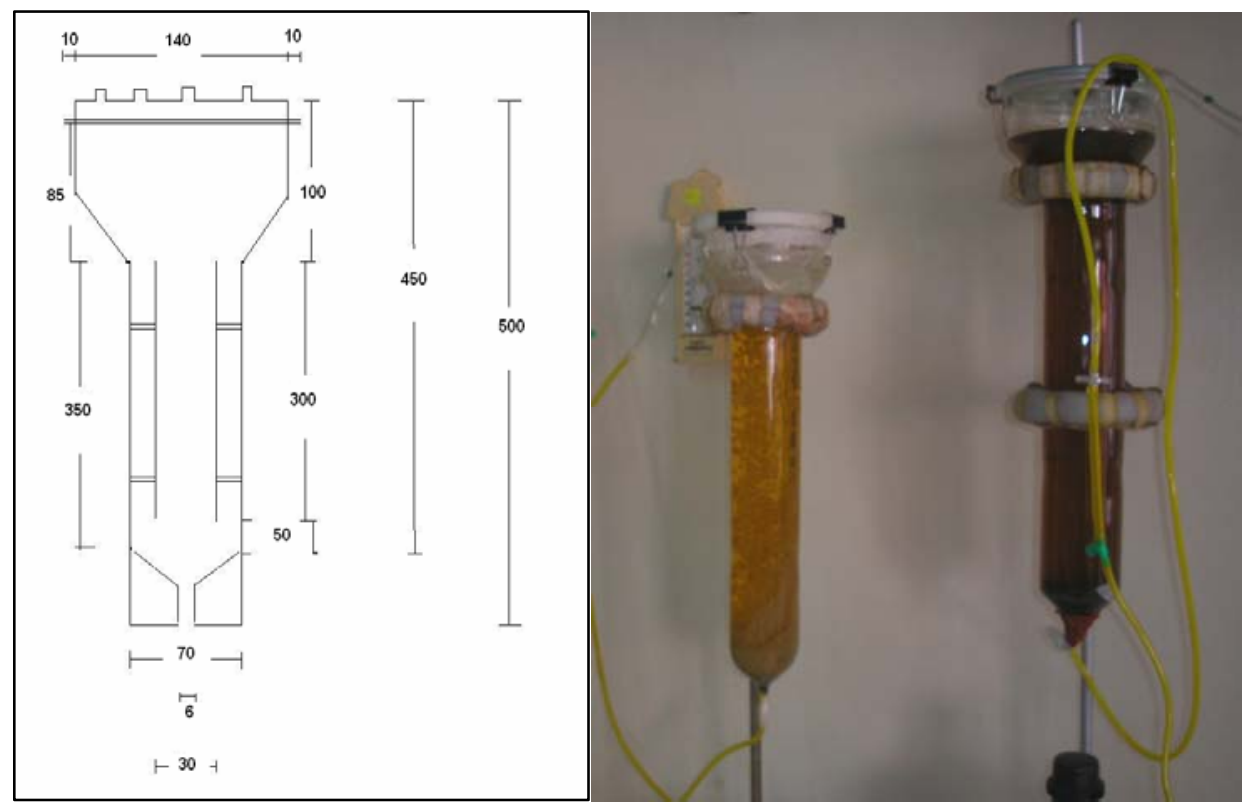

Figure 1. Dimensions of an airlift reactor (a) and airlift reactor inoculated with $A$. discolor for lignin degradation (b).

sodium malonate ( $\mathrm{pH} 4.5), 1 \mathrm{mM}$ DMP, 1 $\mathrm{mM} \mathrm{MnSO} 4$, and up to $600 \mu \mathrm{L}$ of supernatant in a total volume of $1 \mathrm{~mL}$. The reaction was initiated by adding 0.4 $\mathrm{mM} \mathrm{H} \mathrm{H}_{2} \mathrm{O}_{2}$. One $\mathrm{MnP}$ activity unit was defined as the amount of enzyme transforming $1 \mu \mathrm{mol}$ DMP per minute (Moreira et al., 1997).

To evaluate the color of samples of the bioreactor, $1.5 \mathrm{~mL}$ were extracted and filtered through a $0.45 \mu \mathrm{m}$ membrane filter (presence of biomass affected accuracy), and the $\mathrm{pH}$ was adjusted to 7.0 with $\mathrm{H}_{2} \mathrm{SO}_{4}$ or $\mathrm{NaOH}$. The color was determined with a spectrophotometer (Spectronic Genesys 2PC) at $455 \mathrm{~nm}$ using APHA Platinum-Cobalt standard with a range of $0-500$ color units (PCU). One color unit (U Pt-Co) equals $1 \mathrm{mg} \mathrm{L}^{-1}$ platinum as chloroplatinate ion.

Lignin concentration was measured as phenols by UV absorbance at $220 \mathrm{~nm}$. The reaction mixture contained $100 \mu \mathrm{L}$ of sample, previously filtered with $0.45 \mu \mathrm{m}$ membrane filter, and $2 \mathrm{~mL}$ of phosphate buffer at $\mathrm{pH}$ 6.0. The lignin concentration was determined by difference with a control assay (without lignin and with fungus). The color and lignin adsorbed by the biomass after treatment (28 days of incubation) were determined according to the method described by Van Driessel and Christov (2001). pH measurements on 700 to $800 \mu \mathrm{L}$ culture fluid samples were made by using a micro-pH electrode (HANNA HI 1330). Glucose concentration was determined using dinitrosalicylic acid (DNSA) with Dglucose as the standard.

To determine the biomass was used a reactor only for this activity, inoculated with same conditions that the assays for lignin degradation. The sample was collected from reactor at the end of each batch stage by filtration (Whatman GF/C filters, $1.2 \mu \mathrm{m}$ ) of culture medium. After 
filtration, the mycelium was dried to constant weight at $105^{\circ} \mathrm{C}$ and then determined gravimetrically.

PCP extraction from soil was performed as follows: i) $20 \mathrm{~mL}$ hexane:acetone mixture $(1: 1, \mathrm{v} / \mathrm{v})$ were added to each flasks containing soil (10 g) and shaken for $2 \mathrm{~h}$ in order to attain transport of PCP from water or soil to the organic phase, and centrifuged $(2500 \mathrm{rpm}$ for $10 \mathrm{~min}$ ) for the separation of the organic and solid phases; ii) the contents were sonicated for $15 \mathrm{~min}$ for the separation of the organic solvent and aqueous phases; iii) an aliquot of the organic phase was used for PCP analysis.

Residual PCP was analyzed by high performance liquid chromatography (HPLC) with an instrument equipped with a Merck-Hitachi L-7100 pump, a Rheodyne 7725 injector with a $20 \mu \mathrm{L}$ loop, a Merck-Hitachi L-7455 diode array detector operating at $215 \mathrm{~nm}$ and a Hitachi D-7000 data processor. A Lichrosphere $60 \mathrm{RP}$ select B $250 \mathrm{~mm}$ x 4 mm column of $5 \mu \mathrm{m}$ particle size with a LichroCART 4-4 guard column (Merck) was used. The mobile phase consisted of acetonitrile and phosphoric acid (1\% aqueous solution) $1: 1(\mathrm{v} / \mathrm{v})$ with a flow

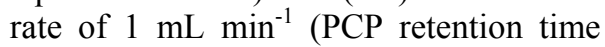
was $12 \mathrm{~min}$ ). Instrument calibrations and quantifications were performed against the pure reference standard (0.05-5 $\left.\mathrm{mg} \mathrm{L}^{-1}\right)$. The procedure described was checked for recovery (which ranged from 86-100\%). Detection limit was $0.03 \mathrm{mg} \mathrm{L} \mathrm{L}^{-1}$, considering the noise-to-signal ratio greater than 2 .

\section{Statistical analysis}

The values reported of PCP removal in contaminated soil are averages of the three determinations expressed on removal percentage. The dates were analyzed with one-way ANOVA test if any significant difference was observed between the groups. In addition ranking of the group was performed with the Duncan's test. The statistical level of significance for all treatment was $5 \%$. Values are reported as means and standard deviation.

\section{RESULTS AND DISCUSSION}

\section{Characteristics of pellets}

In industrial process the adequate morphology for fungi growth is in pellet form, because this form not only reduces the medium viscosity, but also allows the possibility of biomass reuse and thereby continuous operation of the process (Žnidaršic and Pavko, 2001). The Figure 2 shows simple and complex (sawdust and powered activated carbon) pellets of A. discolor. The formed simple pellets were white hollow spheres, instead complex pellets had a black core of powered activated carbon and sawdust surrounded by a white layer of fungal mycelium. Similar results were found by Zhang and $\mathrm{Yu}$ (2000). The authors described that simple pellets of white-rot fungus $T$. versicolor and activated carbon has an empty core. Once the pellet reaches a certain relatively large diameter, the diffusion of nutrient and oxygen into the center of mycelium mass is too slow to maintain the restricted growth of the entire mycelium and the growth occurs mainly in the periphery of the pellets. The hyphae in the center may even die leaving an empty core (Zhang and $\mathrm{Yu}, 2000$ ).

Both pellets (simple and complex) had a diameter from 3 to $5 \mathrm{~mm}$. Several studies have demonstrated that an adequate pellet size allows a high fungus activity and high pollutant degradation (Ha et al., 2001; Moreira et al., 2003; Borràs et al. 2008; Kim and Song, 2009). Borràs et al. (2008), demonstrated that the 


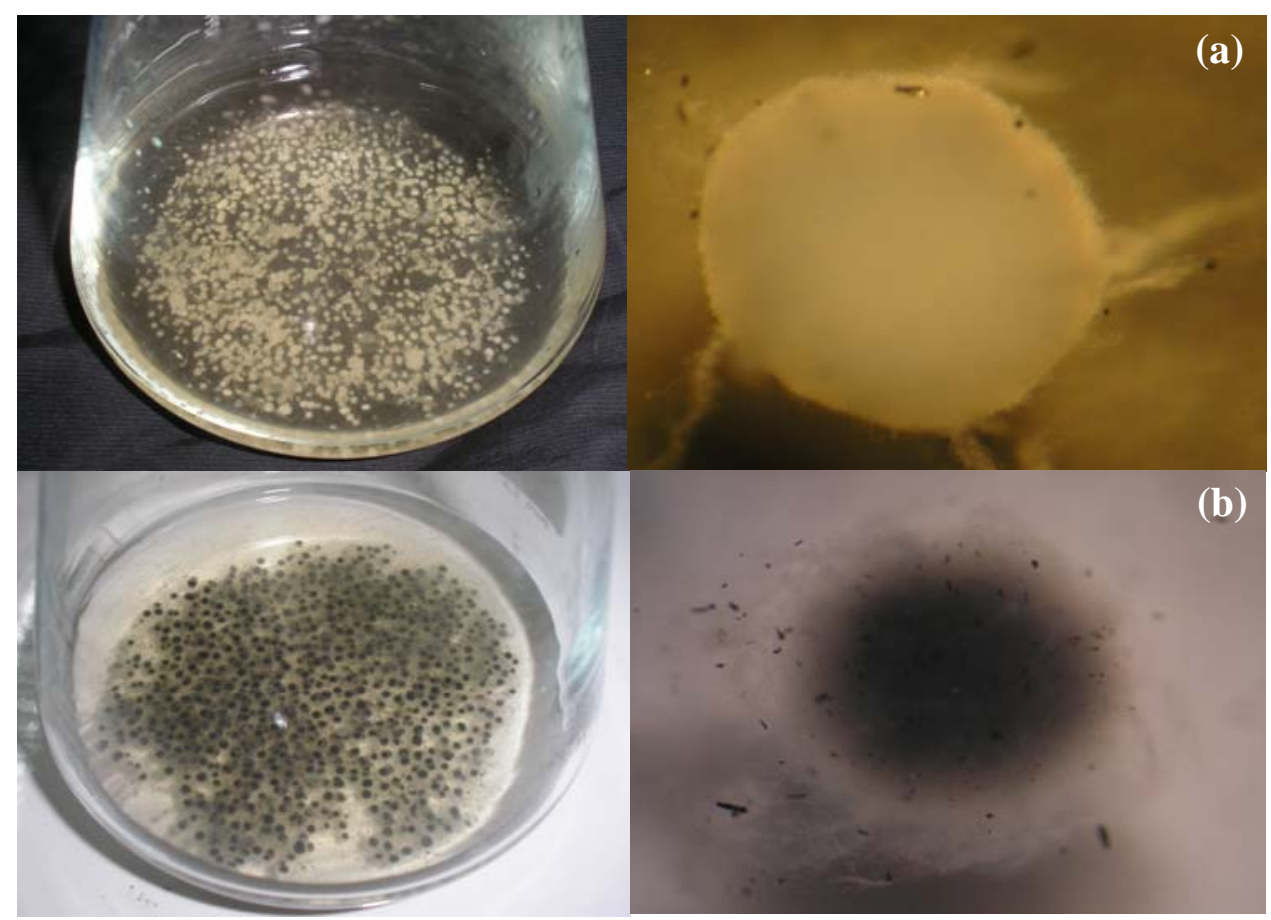

Figure 2. Structure of simple (a) and complex (b) pellets of A. discolor.

pellet of Trametes versicolor of approximately $3 \mathrm{~mm}$ is suitable for applications of dyes and textile wastewater treatment. However, Kim and Song (2009) demonstrated that the rate biodegradation of benzylbutylphethalate and dimethylphthalate by Pleurotus ostreatus were higher in culture with pellets of 1 to $2 \mathrm{~mm}$ than with pellets of 4 to $5 \mathrm{~mm}$. The importance of pellet size is due to substrate limitation in the core of pellet when pellet exceed a critical radius (Moreira et al., 2003).

In this context, the pellets size obtained in this study (simple and complex) could be adequate to be used in degradation processes.
Lignin degradation by simple and complex pellets of $A$. discolor in an airlift bioreactor

In order to evaluate the effectiveness of simple and complex pellets, lignin degradation in an airlift reactor was performed. Lignin was used as model pollutant compound, because it is a residual compound of several productive processes that use wood as raw material, mainly pulp and paper industry. In addition, it is a brown color polymer very difficult to degrade both chemically and biologically (Diez et al., 2002). Moreover, lignin has a chemical structure similar to soil components such as humic and fulvic acids. 
The initial lignin concentration in the airlift reactor was of $1000 \mathrm{mg} \mathrm{L}^{-1}$. The pellets were re-used for two times with the same initial concentration of lignin in each batch, the first cycle was of 20 days and second cycle of 8 days. Figure 3 shows lignin and color removal by simple pellets of $A$. discolor (Figure $3 \mathrm{a}$ ) and $\mathrm{MnP}$ activity, glucose consumption and $\mathrm{pH}$ evolution in the medium (Figure $3 b$ ). In the first cycle lignin and color removal was of 60 and $52 \%$, respectively, whereas in the second cycle lignin and color removal was 24 and $26 \%$, respectively (Figure 3a). In both cycles similar removal rates of lignin and color were obtained, with $28 \mathrm{mg} \mathrm{L}^{-1} \mathrm{~d}$ and $60 \mathrm{U}$ Pt$\mathrm{Co}^{-1} \mathrm{~d}$, respectively.

The more important difference observed between the cycles was the MnP activity. MnP activity reached its maximum at day 14 with $52 \mathrm{U} \mathrm{L}^{-1}$, thereafter it diminished with the time, and was not detected at 28 days.
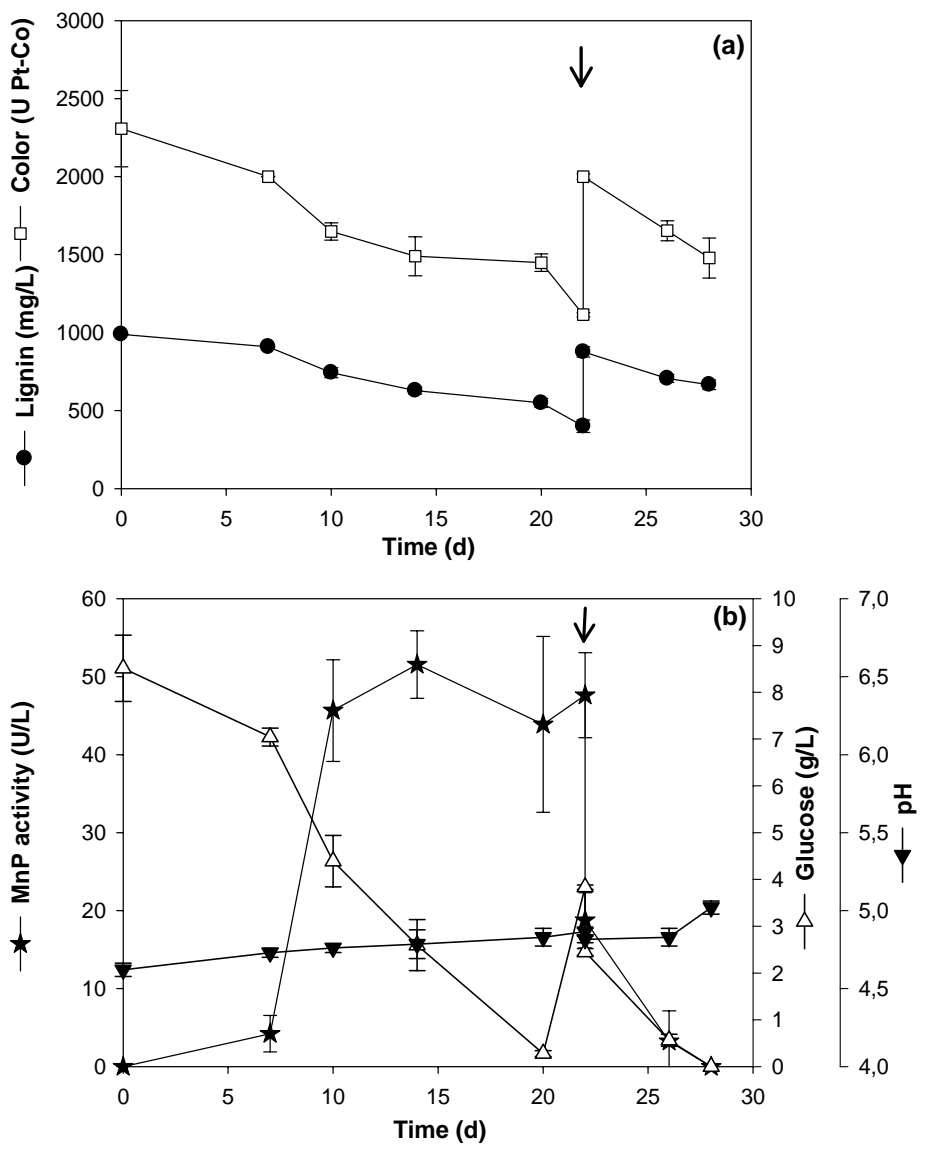

Figure 3. Lignin and color removal (a), MnP production, glucose consumption and $\mathrm{pH}$ (b) of simple pellets of $A$. discolor. 
The low MnP production could be associated to the stress conditions found by the fungus in the bioreactor. The continuous aeration can affect the production of ligninolytic enzymes, changing the fungus morphology and generating rupture of the pellet (Moreira et al., 2003). In this context, diverse studies (Zhang and Yu, 2000; Fomina and Gadd; 2002; Ortega-Clemente et al., 2007) have demonstrated that fungal immobilization in inorganic and/or organic supports allows higher stability of pellet.

The glucose consumption was also evaluated and before glucose depletion 4 $\mathrm{g} \mathrm{L}^{-1}$ of glucose and $0.8 \mathrm{~g} \mathrm{~L}^{-1}$ of peptone at day 20 were added. In the first stage (until 20 days) the glucose consumption rate was $0.45 \mathrm{~g} \mathrm{~L}^{-1} \mathrm{~d}$, whereas in the second stage the consumption rate was $0.98 \mathrm{~g} \mathrm{~L}^{-1} \mathrm{~d}$, being this effect due to high biomass content in the reactor in this period of incubation. This results are corroborated with growth yield on glucose of $0.36 \mathrm{~g}$ biomass $\mathrm{g}^{-1}$ glucose in the first stage, whereas in the second stage was $0.89 \mathrm{~g}$ biomass $\mathrm{g}^{-1}$ glucose. Meanwhile, an about constant $\mathrm{pH}$ of 4.5 was observed for simple pellets with no significant variations with time.

Lignin and color removal by complex pellets of $A$. discolor in a two cycles process is shown in Figure 4a. In the first cycle (20 days) the lignin and color removal was 87 and $62 \%$, respectively, whereas in the second cycle ( 8 days) the lignin and color removal was 72 and 64\%, respectively. Although the removal process in the second cycle was smaller, the removal rate was considerably higher than in the first cycle, being the lignin removal rate of 40 and $88 \mathrm{mg} \mathrm{L}^{-1} \mathrm{~d}$ in the first and second cycle, respectively. Similar results were obtained for color removal rate in the first and second cycle

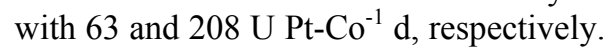
The higher removal rate in the second cycle can be explained by the increase of $\mathrm{MnP}$ activity with a maximal activity of $140 \mathrm{U} \mathrm{L}^{-1}$ at 28 days (Figure 4b). Diverse studies (Ehara et al., 2000; Li et al., 2009) have demonstrated that $\mathrm{MnP}$ enzyme plays an important role in degradation of organic pollutants. In this case, the increase of $\mathrm{MnP}$ activity coincides with glucose depletion (Figure 4b). Several studies have demonstrated that ligninolytic enzyme production is secreted usually at the onset of secondary metabolism phase or idiophase (Camarero et al., 1999). Moreover, the MnP activity of complex pellets was not affected by stress conditions generated in bioreactors as it was observed with simple pellets (Figure 3b), where a change of fungus morphology during the time of incubation was observed. Similarly to what observed with simple pellet a constant $\mathrm{pH}$ at 4.5 was measured through the incubation period (Figure 4b). Ballaminut and Matheus (2007) observed that Psilocybe castanella and Lentinus crinitus grown on solid substrates (lignocellulosic materials) also tend to always maintain an acidic $\mathrm{pH}$.

Lignin and color absorbed by the simple and complex pellets was $<5 \%$, which indicates that the mainly effect was degradation. The previous results seem to indicate that the complex pellets were more effective than simple pellets in the degradation process. Studies development by Ortega-Clemente et al. (2007) demonstrated that pellets immobilized on activated carbon and sawdust, were most stable than pellets without support in either bioreactor with continuous flow feeding and batch feeding mode.

In the complex pellets of $A$. discolor the supports allowed a high enzymatic activity and therefore higher pollutant degradation. Diverse studies have demonstrated that the use of inorganic support (activated carbon for us) provide structural function (Zhang and $\mathrm{Yu}, 2000$; Fomina and Gadd; 2002), and organic 
support (sawdust) provide nutritional function for fungus (Walter et al., 2004, Rubilar et al., 2007; Levin., 2008; Mohammadi and Nasernejad, 2009). Therefore, the complex pellets formulation used in this study, including both the activated carbon and sawdust is an effective alternative for wastewater treatments.
Pentachlorophenol (PCP) removal in soil by simple and complex pellets of $A$. discolor

The bioremediation of contaminated soil by simple and complex pellets of $A$ discolor was evaluated. The used model compound was PCP, because it is a compound produced in bleached kraft
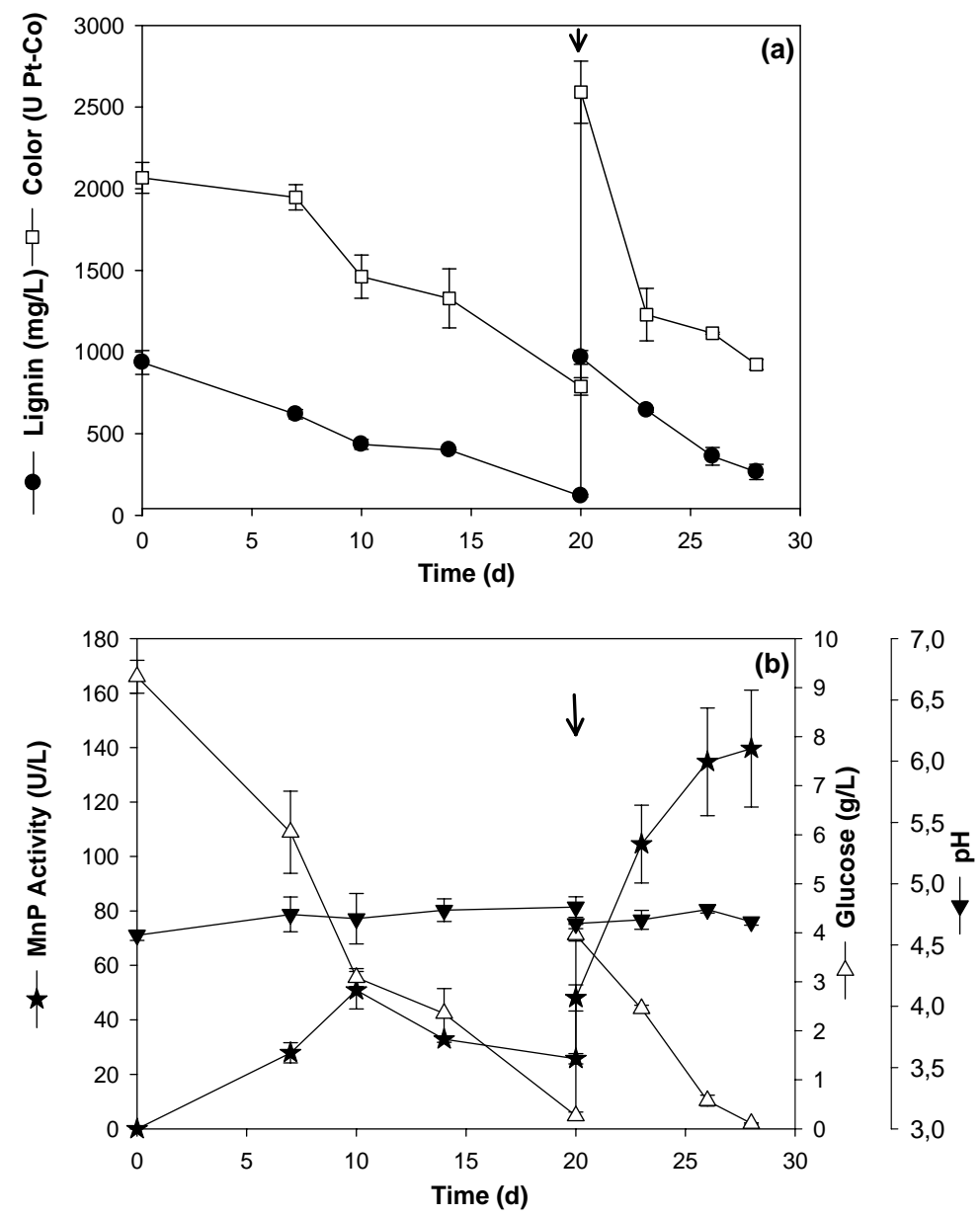

Figure 4. Lignin and color removal (a), MnP production, glucose consumption and $\mathrm{pH}$ (b) of complex pellets of A. discolor. 
mills during lignin degradation by chorination of phenolic residues produced in the pulping and present in the unbleached pulp (Sant'Anna, 1992).

Figure 5 shows the removal of $150 \mathrm{mg}$ $\mathrm{kg}^{-1}$ of PCP in an artificially contaminated soil by simple and complex pellets of $A$. discolor. Before 28 days of bioaugmentation there was a significant PCP reduction by complex pellets $(\mathrm{p}<0.05)$ with $127.5 \mathrm{mg} \mathrm{kg}^{-1}$ of removal, corresponding to $85.1 \pm 7.2 \%$ of the initial amount, whereas the PCP removal by simple pellets was $102.0 \mathrm{mg} \mathrm{kg}{ }^{-1}$, corresponding to $68.3 \pm 4.3 \%$ (Table 2). With complex pellets there was, also, a visual colonization on the surface of the soil, while no fungal growth on the soil was observed with simple pellets.

A removal of about $106.5 \mathrm{mg} \mathrm{kg}^{-1}$ (71.3 $\pm 5.2 \%$ of PCP initial concentration) was measured in natural soil (without pellet) corresponding to the degradation of the pollutant by autochthonous microorganisms of soil. These results indicate that the fungus without support did not survive in soil and the PCP degradation in the treatment with simple pellets could be attributed to the autochthonous soil microflora. Studies developed by McGrath and Singleton (2000) demonstrated that remediation of soil contaminated with PCP by inoculation with $\mathrm{P}$. chrysosporium as free mycelium did not improve the PCP remediation over non-inoculated PCP contaminated soil.

Although complex pellets increased the PCP degradation in soil, the PCP removal cannot be attributed totally to degradation processes. Indeed, the PCP removal in the sterile soil was $76 \mathrm{mg} \mathrm{kg}^{-1}$ $(57.0 \pm 3.9 \%)$, which means retention of the pollutant (Figure 5).

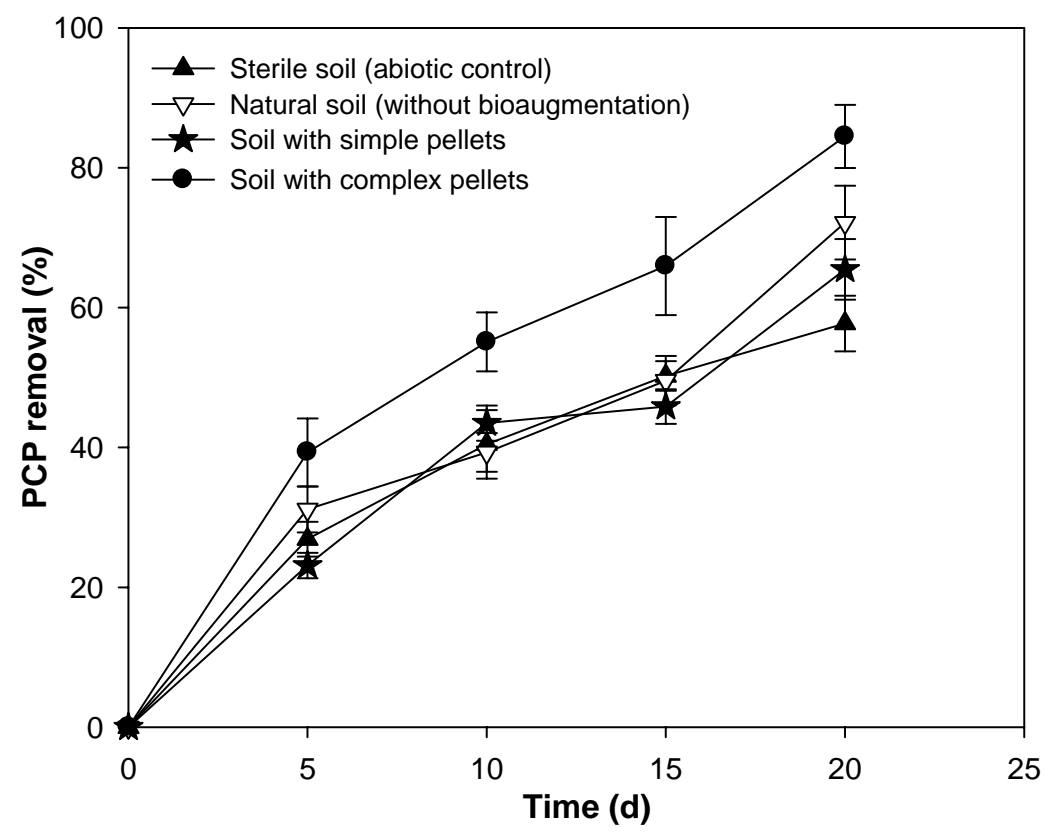

Figure 5. PCP removal $\left(150 \mathrm{mg} \mathrm{kg}^{-1}\right)$ in Andisol soil by simple and complex pellets of A. discolor. 
The ability of soil to retain organic contaminants is attributed to adsorption and chemical reactions occurring on active surfaces of humic substances and mineral particles; some xenobiotics can also be retained through entrapment within the soil matrix (Bollag et al., 1998).

The soil characteristics play an important role in the adsorption and biodegradation processes of chlorophenols in the soil environment. Cea et al. (2005) demonstrated that Chilean Andisol is a good sorbent for chlorophenols, mainly for their high amounts of organic matter and the presence of allophone as main clays component that allows hydrogen bond formation between soil colloids and pentachlorophenol. On the other hand, the adsorption effect occurred mainly during the first days of incubation (Figure 5). A first rapid removal phase during the first 5 days $\left(7.1 \mathrm{mg} \mathrm{kg}^{-1} \mathrm{~d}\right)$, followed by a slower one (2.7 $\left.\mathrm{mg} \mathrm{kg}^{-1} \mathrm{~d}\right)$ was observed.

Results previously obtained have shown that PCP is strongly adsorbed in this type of soil during the first 24 hours of contact (Cea et al., 2005). The MnP activity of simple and complex pellets of A. discolor in soil contaminated with PCP is shown in Figure 6.

The MnP activity was higher in the soil with complex pellets with maximum activity of $0.021 \mathrm{U} \mathrm{g}^{-1}$ soil at $5 \mathrm{~d}$ of bioaugmentation, whereas in soil with simple pellets the maximum activity was $0.009 \mathrm{U} \mathrm{g}^{-1}$ at first day of bioaugmentation. The maximum $\mathrm{MnP}$ activity coincides with the rate PCP removal that was higher during the first 5 days (Figure 5 and 6).

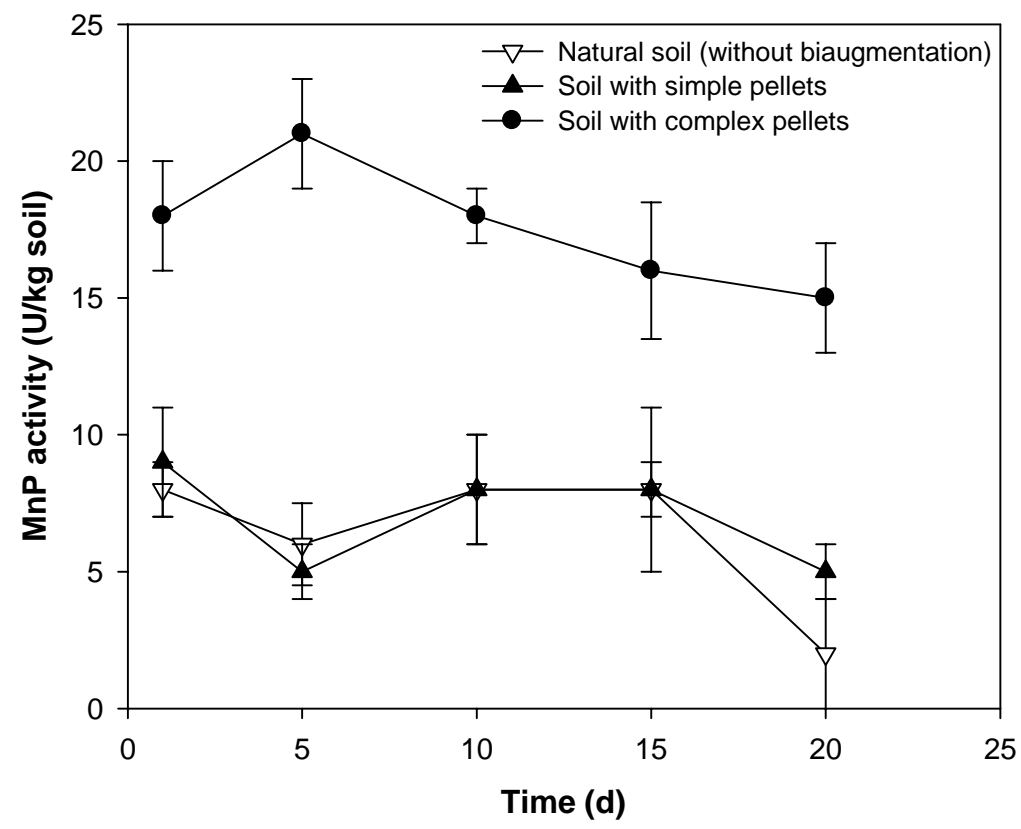

Figure 6. MnP activity of simple and complex pellets of A. discolor in soil contaminated with PCP. 
Table 2. PCP removal ( $\left.150 \mathrm{mg} \mathrm{kg}^{-1}\right)$ in Andisol soil by simple and complex pellets of A. discolor after 28 days of incubation. Different letters indicate a significant difference between treatments based on Duncan`s test $(\mathrm{p}<0.05)$.

\begin{tabular}{lc}
\hline Treatment & PCP removal after 28 days (\%) \\
\hline Soil with complex pellet & $85.1 \pm 7.2 \mathrm{a}$ \\
Soil with simple pellet & $68.3 \pm 4.3 \mathrm{~b}$ \\
Natural soil (without bioaugmentation) & $71.3 \pm 5.2 \mathrm{~b}$ \\
Sterile soil (abiotic control) & $57.0 \pm 3.9 \mathrm{c}$ \\
\hline
\end{tabular}

\section{CONCLUSIONS}

The sawdust and activated carbon were used for A. discolor pellets formation obtaining adequate characteristics of diameter and structure to be used in an airlift reactor. Also, these supports provided stability to the fungus in an airlift reactor, expressed in higher $\mathrm{MnP}$ activity in relation to simple pellet (only mycelium). The degradation of lignin in airlift reactor was higher with complex pellets of A. discolor. Similarly, good results were obtained in the bioremediation of soil contaminated with PCP by complex pellets of $A$. discolor.

In this respect, the fungi growth in activated carbon and sawdust provide stability and nutrient reserve that allow growth and pollutant degradation in soil. Therefore, in conclusion the sawdust and activated carbon are suitable carriers for A. discolor in degradation of organic pollutants in wastewater and soil.

\section{ACKNOWLEDGMENTS}

The authors would like to thank FONDECYT Project No. 3080013 and 1090678.

\section{REFERENCES}

APHA, AWWA, WPCF. 2000. Standard methods for the examination of water and wastewater. 18th Edn., New York.

Ballaminut, N., Matheus, D.R. 2007. Characterization of fungal inoculum used in soil bioremediation. Braz J Microbiol. 38, 248-252.

Bollag, J.M., Dec J., Huang, P.M. 1998. Formation mechanisms of complex organic structures in soil habitats. Adv Agron. 63, 237266.

Borràs, E., Blánquez, P., Sarrà, M., Caminal, G., Vicent, T. 2008. Trametes versicolor pellets production: Low-cost medium and scale-up. Biochem Eng J. 42, 61-66.

Camarero, S., Sarkar, S., Ruiz-Dueñas, F.J., Martínez, M.J., Martínez, A.T. 1999. Description of a versatile peroxidase involved in the natural degradation of lignin that has both manganese peroxidase and lignin peroxidase substrate interaction sites. J Biol Chem. 274, 10324-10330.

Cassidy, M.B., Lee, H., Trevors, J.T. 1996. Environmental applications of immobilized microbial cells: a review. J Ind Microbiol. 16, 79101.

Cea, M., Seaman, J.C., Jara, A.A., Mora, M.L., Diez, M.C. 2005. Describing chlorophenol sorption on variable-charge soil using the triplelayer model. J Colloid Interf Sci. 292, 171-178. 
Diez, M.C., Castillo, G., Aguilar, L., Vidal, G., Mora, M.L. 2002. Operational factors and nutrients effect on activated sludge treatment for phenolic compounds degradation from Pinus radiata kraft mill effluent. Bioresource Technol. 83, 131-138.

Ehara, K., Tsutsumi, Y., Nishida, T. 2000. Role of Tween 80 in biobleaching of unbleached hardwood kraft pulp with manganese peroxidase. J Wood Sci. 46, 137-142.

Fomina, M., Gadd, G.M. 2002. Influence of clays minerals on the morphology of fungal pellets. Mycol Res. 106, 107-117.

Ha, H.C., Honda, Y., Watanabe, T., Kuwahara, M. 2001. Production of manganese peroxidase by pellet culture of the lignindegrading basidiomycete, Pleurotus ostreatus. Appl Microbiol Biotechnol. 55, 704-711.

Kim, Y., Song, H. 2009. Effect of fungal pellet morphology on enzyme activities involved in phthalate degradation. J Microbiol. 47, 420-424.

Lestan, D., Lamar, R.T. 1999. Influence of humidity on production of pelleted fungal inoculum. World J Microbiol Biotechnol. 15, 349-357.

Lestan, D., Lestan, M., Lamar, R.T. 1998. Growth and viability of micelial fragments of white-rot fungi on some hydrogels. J Ind Microbiol Biot. 24, 244-250.

Levin, L., Herrmann, C., Papinutti, L. 2008. Optimization of lignocellulolytic enzyme production by the white-rot fungus Trametes trogii in solid-state fermentation using response surface methodology. Biochem Eng J. 39, 207214.

Li, X.D., Jia, R., Li P.S., Ang, S.S. 2009. Response surface analysis for enzymatic decolorization of Congo red by manganese peroxidase. J Mol Catal B-Enzym. 56, 1-6.

Lin, Y., Liao, W., Chen, S. 2007. Study of pellet formation of filamentous fungi Rhizopus oryzae using a multiple logistic regression model. Biotech Bioeng. 99, 117-128.

McGrath, R., Singleton, I. 2000. Pentachlorophenol transformation in soil: a toxicological assessment. Soil Biol Biochem. 32, 1311-1314.
Milestone, C.B., Stuthridge, T.R., Fulthorpe, R.R. 2007. Role of high molecular mass organics in colour formation during biological treatment of pulp and paper wastewater Water Sci Technol. 55, 191-198.

Moreira, M.T., Feijoo, G., Sierra Alvarez, R., Lema, J., Field, J.A. 1997. Biobleaching of oxygen delignified kraft pulp by several white rot fungal strains. J. Biotechnol. 53, 237-251.

Moreira, M.T., Feijoo, G., Lema, J.M. 2003. Fungal bioreactors: Applications to white-rot fungi. Rev Env Sci Biotechnol. 2, 247-259.

Mohammadi, A., Nasernejad, B. 2009. Enzymatic degradation of anthracene by the white rot fungus Phanerochaete chrysosporium immobilized on sugarcane bagasse. J Hazard Mat. 161, 534-537.

Ortega-Clemente, A., Ponce-Noyola, M.T., Montes-Hoecasitas, M.C., Vicent, M.T., Barrera-Cortés, J., Poggi-Varaldo, H.M. 2007. Semi-continuous treatment of recalcitrant anaerobic effluent from pulp and paper industry using hybrid pellets of Trametes versicolor. Water Sci Technol. 55, 125-133.

Pulp and Paper International. 2005. Annual Review. Vol 47, $\mathrm{N}^{\circ} 7$.

Pointing, S.B. 2001. Feasibility of bioremediation by white-rot fungi. Appl Microbiol Biotechnol. 57, 20-33.

Rubilar, O., Feijoo, G., Diez, C., Lu-Chau, T.A., Moreira, M.T., Lema, J.M. 2007. Biodegradation of pentachlorophenol in soil slurry cultures by Bjerkandera adusta and Anthracophyllum discolor. Ind Eng Chem Res. 46, 6744-6751.

Sant Anna, J. 1992. Biological treatment of pulp and paper industrial wastewaters: Processes and bioreactors. Second Brazilian Symposium on the chemistry of Lignin and other Wood products III, PP. 297-314.

Taylor, T.R., Tucker, T., Whalen, M.M. 2005. Persistent inhibition of human natural killer cell function by ziram and pentachlorophenol. Environ Toxicol. 20, 418-424.

Tortella, G.R., Durán, N., Diez, M.C. 2005. Fungal diversity and use in decomposition of environmental pollutants. Crit Rev Microbiol. 31, 197-212. 
Van Driessel, B., Christov, L. 2001. Decolorization of bleach plant effluent by mucoralean and white-rot fungi in a rotating biological contactor reactor. J Biosci Bioeng. 92, 271-276.

Walter, M., Boul, L., Chong, R., Ford, C. 2004. Growth substrate selection and biodegradation of PCP by New Zealand white-rot fungi. J Environ Manage. 71, 361-369.
Zhang, F., Yu, L. 2000. Decolourisation of acid violet 7 with complex pellets of white rot fungus and activated carbon. Bioprocess Eng. 23, 295 301.

Žnidaršic, P., Pavko, A. 2001. The morphology of filamentous fungi in submerged cultivations as a bioprocess parameter. Food Technol Biotechnol. 39, 237-252. 